\title{
Prognostic instrument for survival outcome in melanoma patients: based on data from the population-based Swedish Melanoma Register
}

\author{
Johan Lyth, R. Mikiver, K. Nielsen, K. Isaksson and C. Ingvar
}

Linköping University Post Print

\section{Tweet}

N.B.: When citing this work, cite the original article.

Original Publication:

Johan Lyth, R. Mikiver, K. Nielsen, K. Isaksson and C. Ingvar, Prognostic instrument for survival outcome in melanoma patients: based on data from the population-based Swedish Melanoma Register, 2016, European Journal of Cancer, (59), 171-178.

http://dx.doi.org/10.1016/j.ejca.2016.02.029

Copyright: Elsevier

http://www.elsevier.com/

Postprint available at: Linköping University Electronic Press

http://urn.kb.se/resolve?urn=urn:nbn:se:liu:diva-128735 
Prognostic instrument for survival outcome in melanoma patients -based on data from the population-based Swedish Melanoma Register

Lyth $\mathrm{J}^{1}$, Mikiver $\mathrm{R}^{2}$, Nielsen $\mathrm{K}^{3}$, Isaksson $\mathrm{K}^{4}$, Ingvar $\mathrm{C}^{4}$

${ }^{1}$ Local Health Care Research and Development Unit, County Council in Östergötland, Linköping, Sweden

${ }^{2}$ Regional Cancer Centre South East Sweden and Department of Clinical and Experimental Medicine, Linköping University, Linköping, Sweden

${ }^{3}$ Department of Dermatology, Helsingborg Hospital, Clinical Sciences, Lund University, Lund, Sweden

${ }^{4}$ Department of Surgery, Skåne University Hospital, Clinical Sciences, Lund University, Lund, Sweden

Correspondence to: Johan Lyth, Local Health Care Research and Development Unit, County of Östergötland, SE-581 85 Linköping, Sweden

Phone: +46-10 103 87 83, Fax: +46-10 1038501

E-mail: johan.lyth@regionostergotland.se

Short title to be used as a 'running head': Prognostic instrument for melanoma survival

Conflicts of Interest and Source of Funding: No conflicts of interest were declared from the authors. This work was supported by Regional Cancer Centre South East in Linköping and from Hudfonden, the S.R Gorthon foundation, The Paulsson Trust and the G. Nilsson foundation.

Word count Abstract: 248 Word count Text: 2,706, tables: 4, figures: 2 


\begin{abstract}
Background: Several major analyses have identified a consistent set of independent risk factors for cutaneous malignant melanoma (CMM). A few prognostic models have been presented but some are based on a limited number of patients and others are based on selected groups of patients referred to major institutions. No nationwide population-based prognostic instrument for survival of CMM has been presented. The Swedish Melanoma Register (SMR) database covers 99\% of CMM diagnosed in Sweden and includes today $>50,000$ cases.
\end{abstract}

Objectives: To create a prognostic instrument based on SMR data in order to give highly reliable risk profiles for patients diagnosed with localised CMM.

Methods: Clinicopathological data was linked to the cause of death registry for calculation of CMM-specific survival. A generalised gamma method was used in order to derive 1,5 and 10-year probabilities of death for each combination of patient and tumour data: age, sex, tumour site, tumour thickness, tumour ulceration, Clark's level of invasion and when applicable also outcome of sentinel node biopsy (SNB). Results: Tumour thickness had the highest prognostic impact, explaining $77 \%$ of the model. Women had 30\% lower risk of death due to CMM than men. Presence of ulceration nearly doubled the risk. If the patient had a positive SNB status the risk of death due to CMM increased 3 times versus a negative SNB status.

Conclusion: This unique population-based prognostic model for primary CMM shows better survival than the AJCC prognostic model widely used. The reason is probably that the referral bias is eliminated in a population-based cohort.

Key words: prognostic instrument; malignant melanoma; population-based; generalised gamma method

Abbreviations used: SMR: Swedish Melanoma Register; CMM: Cutaneous Malignant; MAD: Mean absolute difference; Melanoma; CI: Confidence interval; GG: Generalised Gamma; KM: Kaplan Meier. 


\section{Introduction}

Several major analyses have identified a consistent set of independent risk factors and prognostic factors for cutaneous malignant melanoma (CMM) patients all over the world. (1) Mervic suggests that adding sex, age and tumour site to the AJCCclassification could improve the prediction of an individual patient's prognosis compared to the AJCC staging system currently in use $(1,2)$. A few prognostic instruments have been presented but some are based on a limited number of patients and others are based on selected groups of patients referred to major institutions treating CMM (3-9). Hence, former instruments have not been as generalizable as expected. So far no population-based nationwide prognostic instrument for survival of CMM has been presented.

At present, the Swedish Melanoma Register (SMR) covers almost all (99\%) primary CMMs diagnosed in Sweden and contains >50,000 CMMs. Several reports have been published based on SMR data (10-14). As this database includes information about important risk factors for the CMMs and is linked to the cause of death registry on an individual base, CMM-specific survival could be analysed.

The aim of the study was to create a prognostic instrument based on SMR data in order to give highly reliable risk profiles for patients diagnosed with localised CMM (clinical stages I-II).

\section{Materials and methods}

\section{Data collection}

Sweden, with a population of 10 million people, consists of six different health care regions. For each regional health care region there is also a specific regional cancer centre, which is responsible for cancer registration and the coordination of regional cancer care. Since 1990 the national multiprofessional Swedish Melanoma Study Group has prospectively collected clinicopathological data for all CMM in Sweden. By law both clinicians and pathologists are required to report all cancer diagnoses to the national registry, thereby ensuring a high quality in the reporting (14). Every CMM diagnosis is linked to the patient's unique individual Swedish personal 
identity number. This facilitates a secure linking of records to the Cause of Death Registry (15).

Data from 1990-2014 were used for this study and a total of 47,023 patients with (first) primary CMM, clinical stage I-II, were reported to the SMR. Patients with clinical stage III-IV at diagnosis of the primary CMM were not included due to the small number $(n=1,357)$ of patients and since data for those patients were not fully validated. Furthermore, patients with missing data for any of the parameters required in the model $(n=9,143)$ and patients with CMMs located at hand/foot/subungual $(n=523)$ were excluded, resulting in 37,357 patients for further analyses. The main reason for missing data was that only four out of six health care regions reported ulceration before 2007 .

In order to estimate prognosis after sentinel node biopsy (SNB), a separate data set based on data from 4,505 patients with reported outcome of SNB was created. SNB was first introduced in 1999 in Sweden but was not nationally recommended in the national guidelines until 2007. In Sweden the indication for SNB in thin $(\leq 1.0 \mathrm{~mm})$ CMM has been debated and consequently data are still inconsistent in this group. Thus, to avoid selection bias, the thin CMM that had a SNB performed were not included in our SNB data set.

The following clinicopathological variables from SMR were assessed: age, sex, tumour site, tumour thickness according to Breslow, absence/presence of ulceration, Clark's level of invasion and outcome of SNB when applied. Mitosis was not considered since this information was only available for thin $(\leq 1.0 \mathrm{~mm})$ CMMs from 2009. Date and cause of death until 31 December 2014 were obtained from the Swedish Cause of Death Registry.

\section{Statistical analysis}

In the analyses, age was categorized into five groups $(\leq 39,40-59,60-69,70-79$ and $\geq 80$ years). Tumour thickness was analysed as a categorical variable grouped according to the American Joint Commission on Cancer (AJCC) 2002 classification (16), but with an additional subdivision of T1 into three previously used groups $(<0.5$ $\mathrm{mm}, 0.5-0.8 \mathrm{~mm}$ and $0.81-1.0 \mathrm{~mm}$ ) (12). Tumour sites were divided into three groups (head/neck, trunk and extremities). Upper- and lower extremities were combined 
because there was no significant difference between the two groups. In the SNB data set with fewer observations, age was reduced into two categories based on the median value. Tumour site and Clark's level of invasion were statistically insignificant and were both excluded in the SNB data set. The following variables were included in the SNB data set: tumour thickness, sex, age $(<60, \geq 60)$, tumour ulceration and outcome of SNB.

Survival time was calculated from the date of diagnosis until date of the event or to the date of censoring. In the survival analyses, death from CMM was selected as the primary event. Censoring was made at the following time points: emigration, diagnosis of a second CMM (during the study period), death from causes other than CMM, or the cut-off date, 31 December 2014.

In order to estimate the 1,5 and 10-year CMM-specific survival probabilities a flexible parametric method was used. The generalised gamma (GG) distribution with three parameters was used as being previously recommended for this kind of data (4, 17). As being a parametric method, estimates for 1,440 combinations of prognostic groups could be managed, even for groups with no CMM-specific deaths. From the GG method hazard functions over time for patient's risk profile were also calculated. In order to compare the estimations from the GG method, CMM-specific survival and confidence interval (CI) were estimated using the method of Kaplan and Meier (KM) (18).

For model comparison, the GG model was also estimated by separate models per thickness group. Survival probabilities could also be constructed from a Cox regression and therefore two Cox models were evaluated against GG. One Cox model without significant interactions and a second model including all significant interactions were constructed. For each model the difference between the model specific survival probabilities and KM estimates were calculated for each combination. The models were then assessed using mean absolute difference (MAD) for each time period.

Although the GG method is used to construct the prognostic instrument, it might be difficult to interpret the different parameters in the model. In order to illustrate the risk data, the results from the Cox regression without significant interactions are presented 
showing the prognostic impact (percentage of model $\chi^{2}$ ) for each variable and also the relative importance for each category.

Model specific survival probabilities for GG and KM estimates for combinations with 30 observation or more were illustrated including 1, 5 and 10 years from diagnosis.

\section{Results}

Of the 37,357 patients diagnosed with a first primary invasive CMM between 1990 and 2014, 18,773 (50.3\%) were women and the median age at diagnosis was 63 (range 4-107) years. Tumour thickness was reported in $>97 \%$ of the patients. The majority $(55.7 \%)$ of patients had a thin CMM of $1 \mathrm{~mm}$ or less and $9.9 \%$ of the patients had a tumour of $4 \mathrm{~mm}$ or more. During a median follow-up time of 5.2 (range 0-25) years, 3,375 (9\%) patients died from CMM.

\section{-Insert Table 1 about here-}

From the Cox models, the variable with the highest prognostic impact in localised CMM was tumour thickness, explaining $77 \%$ of the model $\chi^{2}$. In the reduced data set including SNB status, tumour thickness still explained over $50 \%$ of the model $\chi^{2}$ (Table 1). Testing for interactions resulted in five significant interaction terms. Although the model with interaction terms was significantly improved $\left(\chi^{2}=90\right.$, degree of freedom $=29,<.001$ ), the importance of the interaction terms was quite low in relation to the main factors in the model (Table 1). The risk of dying from CMM was 17 times higher if the patient had a CMM with tumour thickness $>4 \mathrm{~mm}$ than if the patient had a tumour thickness $<0.5 \mathrm{~mm}$ (Table 2). If the patient had a positive SNB status, the risk of dying of CMM increased 3 times versus a negative SNB status. Women had 30\% lower risk of dying of CMM than men (HR=0.7 (95\% CI, 0.7-0.8). Presence of tumour ulceration, irrespective of tumour thickness, nearly doubled the risk of dying from CMM $(\mathrm{HR}=1.8(95 \% \mathrm{CI}, 1.7-2.0)$ (Table 2).

\section{-Insert Table 2 about here-}


The four evaluated models showed very similar results regarding MAD. All models, except GG, separated on tumour thickness (2.1\%) showed a MAD value of $2.0 \%$ for the 1 year probabilities. The 5-year MAD varied between $7.2 \%$ (GG complete material) and 7.7\% (Cox with interactions) and the 10-year MAD varied between $9.3 \%$ and $9.5 \%$. The parametric GG model based on the complete material was chosen as the prognostic instrument because of scoring lowest for 1 and 5 year survival and because of its simplicity.

\section{-Insert Table 3 about here-}

For the prognostic instrument based on the GG method, MAD increased by tumour thickness and time from diagnosis and varied from $0.1 \%(<0.5 \mathrm{~mm}, 1$ year probability $)$ to $15 \%$ ( $>4.0 \mathrm{~mm}, 10$ year probability). Only including combinations with 30 or more observations improved the overall MAD and lowered the 10 year probability for $>4.0$ $\mathrm{mm}$ to $8.9 \%$. There were 304 combinations with 30 or more observations including 31,304 (84\%) patients. Fig.1 illustrates the difference between the survival probabilities from the GG model and KM estimates for combinations with 30 observations or more.

For the SNB model, MAD for 1, 5 and 10 years were $2.2 \%, 5.5 \%$ and $6.9 \%$, respectively.

\section{-Insert Fig.1 about here-}

The construction of the corresponding instrument for possible online use was also programmed (Fig.2). Simply by entering clinicopathological parameters for the patient (age, sex, tumour site, tumour thickness, Clark's level of invasion, tumour ulceration and SNB status) the program could instantly provide the estimated 1-, 5- and 10-year CMM-specific survival probabilities with $95 \% \mathrm{CI}$. Some examples of predicted survival probabilities are shown in Table 4 . For instance, for a man 54 years of age with $0.8 \mathrm{~mm}$ non-ulcerated extremity CMM and Clark III, the predicted 1, 5, and 10year survival probabilities are 100\% (95\% CI, 100-100), 99\% (95\% CI, 99-99), and 97\% (95\% CI, 97-98), respectively. In contrast, for a woman 60 years of age with a $7.0 \mathrm{~mm}$ ulcerated extremity CMM and Clark IV, the predicted 1, 5, and 10-year 
survival probabilities are 94\% (95\% CI, 93-95), 72\% (95\% CI, $69-74)$, and 57\% (95\% CI, 54-60), respectively.

\section{-Insert Fig.2 about here-}

\section{-Insert Table 4 about here-}

\section{Discussion}

This is the first population-based nationwide prognostic instrument presenting 1,5 and 10-year survival probabilities for localised primary CMM. Furthermore, it is the largest instrument based on more than 37,000 patients and nearly 3,400 CMM deaths. As a complement a second data set was used, including the outcome of SNB for patients with a tumour thickness $>1.0 \mathrm{~mm}$. The corresponding instrument was also programmed for online use.

Prognostic groups were constructed, based on all combinations of age, sex, tumour site, tumour thickness, absence/presence of ulceration and Clark's level of invasion. The MAD for 5-year survival was $7.2 \%$, but was improved to $3.7 \%$ if only combinations with 30 or more observations were used ( $84 \%$ of the patients). The reason for the improvement was that the majority of combinations included few patients, resulting in uncertain KM estimates. Including all relevant prognostic parameters makes predictions more accurate but it also creates several combinations with a higher MAD.

From the Cox analysis, tumour thickness was the dominating risk factor in the model. Also after adjusting for tumour thickness, Clark's level of invasion and tumour ulceration, women had a 30\% lower risk of CMM-related death than men. This superior non-stage effect for women has previously been found in studies with similar HR $(19,20)$. Surprisingly, sex was not included in the final prognostic model in two of the largest published prognostic instruments based on AJCC data and from Queensland Australia respectively $(3,4)$.

When comparing the results in our study with those previously presented by Soong et al., we found that survival data from AJCC was consistently lower (worse) than the Swedish population-based survival data. For instance, the 10-year survival probability for a women 75 years of age with a $2.2 \mathrm{~mm}$ non-ulcerated CMM in the present study 
was $79 \%$ (76-82) compared with $60 \%$ (51-69) in the study by Soong (4). Other studies have previously found such disparities and the most probable explanation is selection bias. The AJCC results are based on a selected data set of patients, probably due to inclusion of patients referred to the institution for metastatic disease and not primarily treated at that institution $(12,21)$. Comparing the results in our population-based study with the population-based prognostic survival model from Queensland, Australia, we find quite similar results. Likewise, Baade et al. also presented a higher estimated survival for the same patient and tumour characteristics compared with the survival from the AJCC prognostic model (3).

The MAD varied with tumour thickness and $>4.0 \mathrm{~mm}$ had the highest difference between survival probabilities from GG and the KM estimates. Including the outcome of SNB improved the MAD for patients with thicker tumours.

The 10-year survival probabilities are by definition based on older data. The CMMspecific survival in Sweden has been quite stable over the study period. Although there has been an increased survival in general for men, this is probably explained by the increasing frequency of thinner CMMs in Swedish men over time. Very few good oncological systemic treatments existed during the study time period until recent years and in Sweden the stage-specific survival has not yet increased (10). However, in the last few years several new medications have been approved for patients with metastatic disease (22). Unfortunately it is too early to assess the impact of these treatments with the present data. As the prognostic instrument is being updated each year by new survival data, we hope in the next few years to see a positive effect of new treatments on survival. Each year more than 3,500 new CMM patients will also be added to the prognostic instrument.

In the present work, models without interaction terms were chosen, mainly due to their limited additional value. The separated GG model did not improve the prognostic accuracy compared with the model computed on the complete material. The fact that the additional value of the interaction terms was limited could explain why the separated model did not improve accuracy.

In the latest AJCC Melanoma Staging and Classification, mitosis was added as a prognostic variable for $\mathrm{CMM} \leq 1.0 \mathrm{~mm}$ (2). Unfortunately, mitosis was not included as 
a variable in SMR until 2009 and hence it was too early to include this variable in this version of our prognostic instrument. This is a current limitation of the study. However, in a few years mitosis is planned to be evaluated as a parameter for the prognostic instrument.

In our study two different prognostic models were constructed, one without the outcome of SNB and the other with the outcome of SNB. The model without the outcome of SNB might be highly relevant for physicians informing the patients with thin $(\leq 1.0 \mathrm{~mm}) \mathrm{CMM}$ of their prognosis. For patients with tumours $(>1 \mathrm{~mm})$, where the SNB outcome is included in the model, the prognostic information is further improved.

In a recent study Crocetti et al. showed that data on the 5-year relative survival after a CMM diagnosis is quite similar for Northern Europe (88\%), Central Europe $(88 \%)$ and Ireland and UK (86\%) (23). The CMM incidence is also quite similar between these regions (24). This indicates that our prognostic instrument probably could be valid for patients in all these countries and regions. Just as in Sweden there are other population-based registers found in Europe (25). A future collaboration with these registers would be of great value in order to assess the generalisability of our model. As many treatment guidelines today are based only on the highly selected AJCC data, which could lead to biased recommendations for staging and adjuvant therapies, it is important also to present population-based prognostic models like ours.

In conclusion, to supply the demand among physicians handling CMM patients we have developed a unique population-based prognostic instrument regarding survival after CMM diagnosis. The prognostic instrument is planned to be open access and might well be a better alternative for prognostic information for European CMM patients than the present AJCC staging which is standard today. Besides the obvious clinical use, healthcare planners and researchers could use this prognostic information in the planning of studies. In the future it might even serve as a help to evaluate new interventions and treatments for CMM patients. 


\section{Acknowledgements}

This work was supported by Regional Cancer Centre South East in Linköping and from Hudfonden, the S.R Gorthon foundation, The Paulsson Trust and the G. Nilsson foundation. Further contributing regional cancer centres were Southern region (Lund), Western region (Göteborg), Stockholm-Gotland region (Stockholm), Uppsala-Örebro region (Uppsala) and the Northern region (Umeå).

\section{Role of the Funding Source}

The sponsors had no involvement in study design, data collection, analysis or interpretation of data, in writing the manuscript or deciding to submit the manuscript.

\section{Conflict of interest statement}

None declared. 


\section{References}

1. Mervic L. Prognostic factors in patients with localized primary cutaneous melanoma. Acta Dermatovenerol Alp Pannonica Adriat 2012;21(2):27-31.

2. Balch CM, Gershenwald JE, Soong SJ, Thompson JF, Atkins MB, Byrd DR, et al. Final Version of 2009 AJCC Melanoma Staging and Classification. Journal of Clinical Oncology 2009;27(36):6199-6206.

3. Baade PD, Royston P, Youl PH, Weinstock MA, Geller A, Aitken JF. Prognostic survival model for people diagnosed with invasive cutaneous melanoma. Bmc Cancer 2015;15(1):27.

4. Soong SJ, Ding SL, Coit D, Balch CM, Gershenwald JE, Thompson JF, et al. Predicting Survival Outcome of Localized Melanoma: An Electronic Prediction Tool Based on the AJCC Melanoma Database. Annals of Surgical Oncology 2010;17(8):2006-2014.

5. Sahin S, Rao B, Kopf AW, Lee E, Rigel DS, Nossa R, et al. Predicting ten-year survival of patients with primary cutaneous melanoma: corroboration of a prognostic model. Cancer 1997;80(8):1426-31.

6. Schuchter L, Schultz DJ, Synnestvedt M, Trock BJ, Guerry D, Elder DE, et al. A prognostic model for predicting 10-year survival in patients with primary melanoma. The Pigmented Lesion Group. Ann Intern Med 1996;125(5):369-75.

7. Barnhill RL, Fine JA, Roush GC, Berwick M. Predicting five-year outcome for patients with cutaneous melanoma in a population-based study. Cancer 1996;78(3):427-32.

8. MacKie RM, Aitchison T, Sirel JM, McLaren K, Watt DC. Prognostic models for subgroups of melanoma patients from the Scottish Melanoma Group database 1979-86, and their subsequent validation. Br J Cancer 1995;71(1):173-6.

9. Clark WH, Jr., Elder DE, Guerry Dt, Braitman LE, Trock BJ, Schultz D, et al. Model predicting survival in stage I melanoma based on tumor progression. J Natl Cancer Inst 1989;81(24):1893-904.

10. Lyth J, Eriksson H, Hansson J, Ingvar C, Jansson M, Lapins J, et al. Trends in cutaneous malignant melanoma in Sweden 1997-2011: thinner tumours and improved survival among men. British Journal of Dermatology 2015;172(3):700-706.

11. Eriksson H, Lyth J, Mansson-Brahme E, Frohm-Nilsson M, Ingvar C, Lindholm C, et al. Later stage at diagnosis and worse survival in cutaneous malignant melanoma among men living alone: a nationwide population-based study from sweden. Journal of Clinical Oncology 2014;32(13):1356-64.

12. Lyth J, Hansson J, Ingvar C, Mansson-Brahme E, Naredi P, Stierner U, et al. Prognostic subclassifications of T1 cutaneous melanomas based on ulceration, tumour thickness and Clark's level of invasion: results of a population-based study from the Swedish Melanoma Register. Br J Dermatol 2013;168(4):779-86.

13. Eriksson H, Lyth J, Mansson-Brahme E, Frohm-Nilsson M, Ingvar C, Lindholm C, et al. Low level of education is associated with later stage at diagnosis and reduced survival in cutaneous malignant melanoma: A nationwide population-based study in Sweden. European Journal of Cancer 2013;49(12):2705-2716.

14. Lindholm C, Andersson R, Dufmats M, Hansson J, Ingvar C, Moller T, et al. Invasive cutaneous malignant melanoma in Sweden, 1990-1999 - A prospective, population-based study of survival and prognostic factors. Cancer 2004;101(9):2067-2078. 
15. Ludvigsson JF, Otterblad-Olausson P, Pettersson BU, Ekbom A. The Swedish personal identity number: possibilities and pitfalls in healthcare and medical research. European Journal of Epidemiology 2009;24(11):659-67.

16. Balch CM, Buzaid AC, Soong SJ, Atkins MB, Cascinelli N, Coit DG, et al. Final version of the American Joint Committee on Cancer staging system for cutaneous melanoma. Journal of Clinical Oncology 2001;19(16):36353648.

17. Ding S, Soong SJ, Lin HY, Desmond R, Balch CM. Parametric modeling of localized melanoma prognosis and outcome. J Biopharm Stat 2009;19(4):732-47.

18. Kaplan EL, Meier P. Nonparametric Estimation from Incomplete Observations. Journal of the American Statistical Association 1958;53(282):457-81.

19. Joosse A, Collette S, Suciu S, Nijsten T, Patel PM, Keilholz U, et al. Sex is an independent prognostic indicator for survival and relapse/progression-free survival in metastasized stage III to IV melanoma: a pooled analysis of five European organisation for research and treatment of cancer randomized controlled trials. J Clin Oncol 2013;31(18):2337-46.

20. Joosse A, Collette S, Suciu S, Nijsten T, Lejeune F, Kleeberg UR, et al. Superior outcome of women with stage I/II cutaneous melanoma: pooled analysis of four European Organisation for Research and Treatment of Cancer phase III trials. J Clin Oncol 2012;30(18):2240-7.

21. de Vries E, Houterman S, Nijsten T, Janssen M, Eggermont A, Coebergh J. Population-based survival of melanoma: much better survival rates than estimated by the AJCC. Melanoma Research 2006;16:S22.

22. Menzies AM, Long GV. Systemic treatment for BRAF-mutant melanoma: where do we go next? Lancet Oncol 2014;15(9):70072-5.

23. Crocetti E, Mallone S, Robsahm TE, Gavin A, Agius D, Ardanaz E, et al. Survival of patients with skin melanoma in Europe increases further: Results of the EUROCARE-5 study. Eur J Cancer 2015.

24. Erdmann F, Lortet-Tieulent J, Schuz J, Zeeb H, Greinert R, Breitbart EW, et al. International trends in the incidence of malignant melanoma 1953-2008-are recent generations at higher or lower risk? International Journal of Cancer 2013;132(2):385-400.

25. Siesling S, Louwman WJ, Kwast A, van den Hurk C, O'Callaghan M, Rosso S, et al. Uses of cancer registries for public health and clinical research in Europe: Results of the European Network of Cancer Registries survey among 161 population-based cancer registries during 2010-2012. Eur J Cancer 2015;51(9):1039-49. 


\section{Tables}

Table 1. Multivariable Cox regression analyses and prognostic impact of variables for the complete material, without/with interactions, and with the subset of sentinel node biopsy (SNB) data

\begin{tabular}{|c|c|c|c|c|c|c|c|c|c|c|c|c|}
\hline \multirow[b]{2}{*}{ Variable } & \multicolumn{4}{|c|}{ Without interactions $(n=37,357)$} & \multicolumn{4}{|c|}{ With interactions $(n=37,357)$} & \multicolumn{4}{|c|}{ SNB data $(n=4,505)$} \\
\hline & $\begin{array}{c}\text { Degree } \\
\text { of } \\
\text { freedom }\end{array}$ & $\begin{array}{l}\text { X2 values } \\
\text { (Likelihood } \\
\text { ratio) }\end{array}$ & $\begin{array}{c}p \\
\text { value }\end{array}$ & $\begin{array}{c}\text { Model } \\
\text { explanation }\end{array}$ & $\begin{array}{c}\text { Degree } \\
\text { of } \\
\text { freedom }\end{array}$ & $\begin{array}{c}\text { X2 values } \\
\text { (Likelihoo } \\
\text { d ratio) }\end{array}$ & $\begin{array}{c}p \\
\text { value }\end{array}$ & $\begin{array}{c}\text { Model } \\
\text { explanation }\end{array}$ & $\begin{array}{c}\text { Degree } \\
\text { of } \\
\text { freedom }\end{array}$ & $\begin{array}{c}\text { X2 values } \\
\text { (Likelihoo } \\
\text { d ratio) }\end{array}$ & $\begin{array}{c}p \\
\text { value }\end{array}$ & $\begin{array}{l}\text { Model } \\
\text { explanation }\end{array}$ \\
\hline Tumour thickness & 5 & 4,097 & $<.001$ & $77 \%$ & 5 & 4,097 & $<.001$ & $76 \%$ & 2 & 293 & $<.001$ & $55 \%$ \\
\hline Age (categorical) & 4 & 576 & $<.001$ & $11 \%$ & 4 & 576 & $<.001$ & $11 \%$ & 1 & 22 & $<.001$ & $4 \%$ \\
\hline Sex & 1 & 289 & $<.001$ & $5 \%$ & 1 & 289 & $<.001$ & $5 \%$ & 1 & 37 & $<.001$ & $7 \%$ \\
\hline Tumour ulceration & 1 & 245 & $<.001$ & $5 \%$ & 1 & 245 & $<.001$ & $5 \%$ & 1 & 43 & $<.001$ & $8 \%$ \\
\hline Clark's level of invasion & 3 & 91 & $<.001$ & $2 \%$ & 3 & 91 & $<.001$ & $2 \%$ & - & - & $<.001$ & - \\
\hline Tumour site & 2 & 28 & $<.001$ & $1 \%$ & 2 & 28 & $<.001$ & $1 \%$ & 1 & - & $<.001$ & - \\
\hline Outcome of SNB & - & - & - & - & - & - & - & - & - & 139 & - & $26 \%$ \\
\hline $\begin{array}{l}\text { Interaction: Thickness * site } \\
\text { Interaction: Thickness * }\end{array}$ & - & - & - & - & 10 & 26 & .004 & $<1 \%$ & - & - & - & - \\
\hline ulceration & - & - & - & - & 5 & 20 & .001 & $<1 \%$ & - & - & - & - \\
\hline Interaction: Sex * age & - & - & - & - & 4 & 10 & .05 & $<1 \%$ & - & - & - & - \\
\hline Interaction: Sex * site & - & - & - & - & 2 & 15 & $<.001$ & $<1 \%$ & - & - & - & - \\
\hline Interaction: Age * site & - & - & - & - & 8 & 19 & .015 & $<1 \%$ & - & - & - & - \\
\hline Total & 16 & 5,326 & & $100 \%$ & 45 & 5,416 & & $100 \%$ & 6 & 534 & & $100 \%$ \\
\hline
\end{tabular}

Data from the Swedish Melanoma Register 1990-2014 with follow-up until 31 Dec 2014 by the Swedish Cause of Death Registry. 


\begin{tabular}{|c|c|c|c|c|c|c|c|c|}
\hline & \multicolumn{4}{|c|}{ Without interactions $(n=37,357)$} & \multicolumn{4}{|c|}{ SNB data $(n=4,505)$} \\
\hline & $\begin{array}{l}\text { Number of } \\
\text { patients }\end{array}$ & $\begin{array}{c}\text { Number of CMM } \\
\text { deaths (\%) }\end{array}$ & $\begin{array}{c}\text { 5-year CMM-specific } \\
\text { survival }\end{array}$ & $\begin{array}{l}\text { Multivariable } \\
\mathrm{HR}(95 \% \mathrm{Cl})\end{array}$ & $\begin{array}{l}\text { Number of } \\
\text { patients }\end{array}$ & $\begin{array}{c}\text { Number of CMM } \\
\text { deaths }(\%)\end{array}$ & $\begin{array}{c}\text { 5-year CMM- } \\
\text { specific survival }\end{array}$ & $\begin{array}{l}\text { Multivariable } \\
\text { HR }(95 \% \mathrm{CI})\end{array}$ \\
\hline \multicolumn{9}{|c|}{ 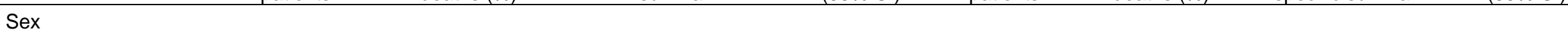 } \\
\hline Men & 18,584 & $2,100(11.3)$ & $88(88-89)$ & 1 (ref) & 2,401 & $319(13.3)$ & $81(79-84)$ & 1 (ref) \\
\hline Women & 18,773 & $1,275(6.8)$ & $94(93-94)$ & $0.7(0.7-$ & 2,104 & $169(8.0)$ & $89(87-91)$ & $0.7(0.6-0.9)$ \\
\hline \multicolumn{9}{|l|}{ Age (years) } \\
\hline$<40$ & 4,482 & $254(5.7)$ & $96(95-96)$ & 1 (ref) & - & - & - & - \\
\hline $40-59$ & 11,620 & $845(7.3)$ & $94(94-95)$ & $1.1(0.9-$ & - & - & - & - \\
\hline $60-69$ & 8,279 & $752(9.1)$ & $92(91-92)$ & $1.2(1.0-$ & - & - & - & - \\
\hline $70-79$ & 7,519 & $887(11.8)$ & $87(86-88)$ & $1.4(1.2-$ & - & - & - & - \\
\hline$\geq 80$ & 5,457 & $637(11.7)$ & $83(82-85)$ & $1.5(1.3-$ & - & - & - & - \\
\hline \multicolumn{9}{|c|}{ Tumour thickness (mm) } \\
\hline$<0.50$ & 9,592 & $105(1.1)$ & $99(99-99)$ & 1 (ref) & - & - & - & - \\
\hline $0.50-0.80$ & 7,631 & $161(2.1)$ & $99(98-99)$ & $1.6(1.2-$ & - & - & - & - \\
\hline $0.81-1.00$ & 3,575 & $184(5.1)$ & $96(96-97)$ & $3.3(2.5-$ & - & - & - & - \\
\hline $1.01-2.00$ & 7,595 & $681(9.0)$ & $92(92-93)$ & $5.0(3.9-$ & 2,257 & $85(3.8)$ & $95(93-96)$ & 1 (ref) \\
\hline $2.01-4.00$ & 5,268 & $1,091(20.7)$ & $78(77-80)$ & $10(7.8-$ & 1,456 & $196(13.5)$ & $82(79-84)$ & $2.4(1.8-3.1)$ \\
\hline$>4.00$ & 3,696 & $1,153(31.2)$ & $61(59-63)$ & $17(13-$ & 792 & $207(26.1)$ & $63(59-68)$ & $4.6(3.5-6.1)$ \\
\hline \multicolumn{9}{|l|}{ Tumour site } \\
\hline Head/neck & 4,641 & $506(10.9)$ & $93(92-93)$ & 1 (ref) & - & - & - & - \\
\hline Extremities & 15,765 & $1,206(7.6)$ & $89(87-90)$ & $0.9(0.8-$ & - & - & - & - \\
\hline Trunk & 16,951 & $1,663(9.8)$ & $91(90-91)$ & $1.1(1.0-$ & - & - & - & - \\
\hline \multicolumn{9}{|l|}{ Tumour ulceration } \\
\hline Absent & 29,813 & $1,593(5.3)$ & $95(95-96)$ & 1 (ref) & 2,923 & $188(6.4)$ & $91(89-92)$ & 1 (ref) \\
\hline Present & 7,544 & $1,782(23.6)$ & $74(73-75)$ & $1.8(1.7-$ & 1,582 & $300(19.0)$ & $74(71-77)$ & $1.8(1.5-2.2)$ \\
\hline \multicolumn{9}{|c|}{ Clark's level of invasion } \\
\hline II & 11,122 & $172(1.5)$ & 99 (99 - 99) & 1 (ref) & - & - & - & - \\
\hline III & 13,175 & $841(6.4)$ & $95(94-95)$ & $1.4(1.2-$ & - & - & - & - \\
\hline IV & 11,606 & $1,919(16.5)$ & $83(82-83)$ & $1.9(1.5-$ & - & - & - & - \\
\hline V & 1,454 & $443(30.5)$ & $62(59-65)$ & $2.4(1.9-$ & - & - & - & - \\
\hline \multicolumn{9}{|l|}{ Outcome of SNB } \\
\hline Negative result & & & & - & 3,618 & $261(7.2)$ & $90(89-91)$ & 1 (ref) \\
\hline Positive result & & & & - & 887 & $227(25.6)$ & $64(59-68)$ & $3.1(2.6-3.8)$ \\
\hline \multicolumn{9}{|l|}{ Age (SNB) } \\
\hline$<60$ years & & & & - & 1,901 & $165(8.7)$ & $88(86-90)$ & 1 (ref) \\
\hline$\geq 60$ years & & & & - & 2,604 & $323(12.4)$ & $82(80-84)$ & $1.3(1.1-1.6)$ \\
\hline
\end{tabular}

Data from the Swedish Melanoma Register 1990-2014 with follow-up until 31 Dec 2014 by the Swedish Cause of Death Registry. 
Table 3. Mean absolute difference (MAD) between survival probabilities from the Generalised Gamma (GG) method and Kaplan-Meier (KM) estimates with corresponding 95\% confidence interval $(\mathrm{Cl})$ per year after diagnosis for the prognostic instrument without and with outcome on sentinel node biopsy (SNB) both based on the Generalised Gamma method ( $n=37,357$ and $\mathrm{n}=4,505$ )

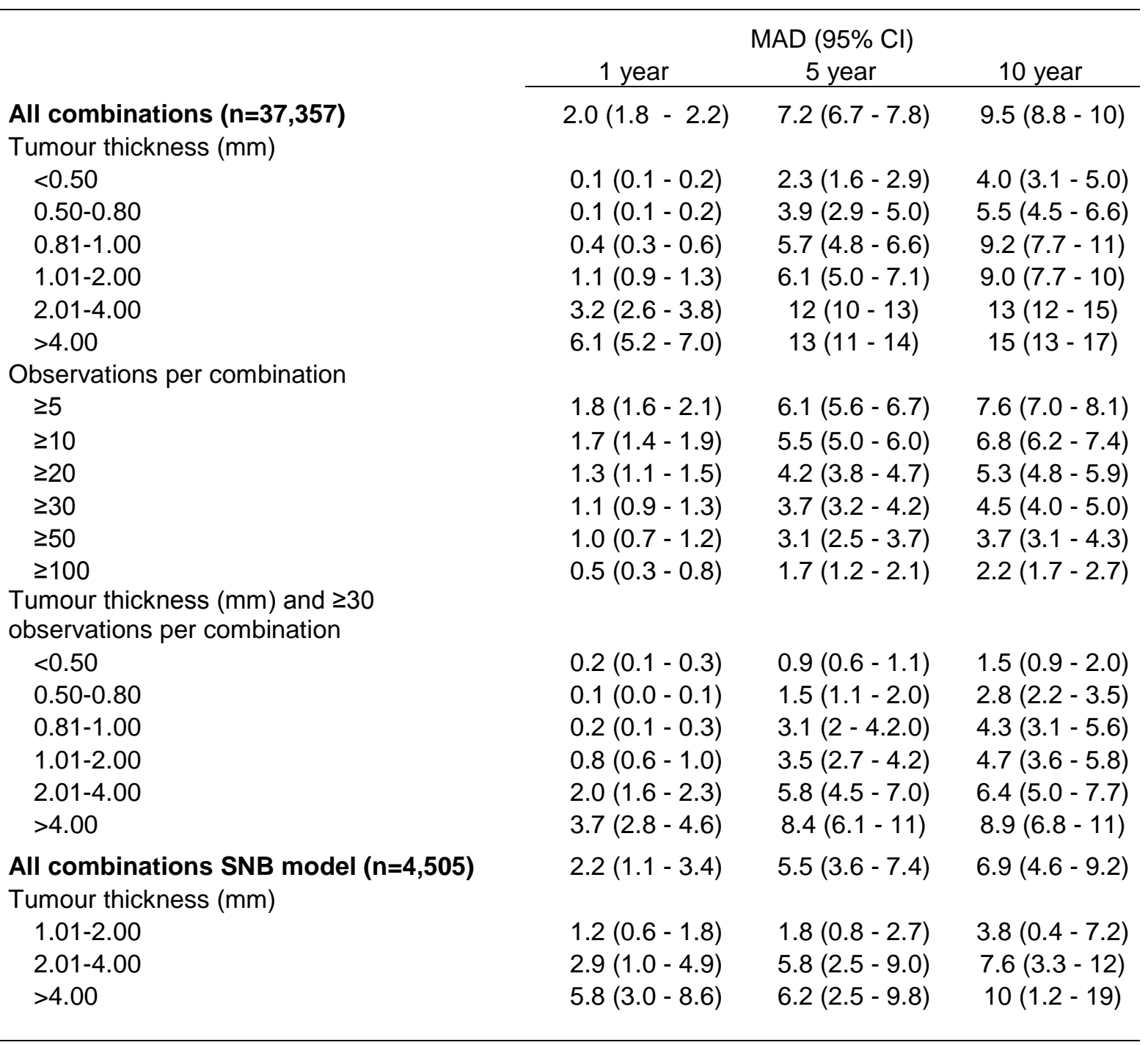

Data from the Swedish Melanoma Register 1990-2014 with follow-up until 31 Dec 2014 by the Swedish Cause of Death Registry. 
Table 4. Examples of predicted 1, 5 and 10-year survival probabilities for patients with localised cutaneous malignant melanoma (CMM)

\begin{tabular}{|c|c|c|c|c|c|c|c|c|c|}
\hline \multirow[t]{2}{*}{ Patient } & \multirow[t]{2}{*}{ Sex } & \multirow[t]{2}{*}{ Age } & \multirow[t]{2}{*}{ Tumour site } & \multirow{2}{*}{$\begin{array}{l}\text { Tumour } \\
\text { thickness }\end{array}$} & \multirow{2}{*}{$\begin{array}{l}\text { Tumour } \\
\text { ulceration }\end{array}$} & \multirow{2}{*}{$\begin{array}{c}\text { Clark's } \\
\text { level of } \\
\text { invasion }\end{array}$} & \multicolumn{3}{|c|}{ Survival probabilities (\%) $(95 \% \mathrm{Cl})$} \\
\hline & & & & & & & 1 year & 5 year & 10 year \\
\hline 1 & Woman & 45 & Extremities & 0.4 & No & ॥ & $100(100-100)$ & $100(100-100)$ & $99(99-100)$ \\
\hline 2 & Woman & 55 & Head/neck & 0.7 & Yes & III & $100(100-100)$ & $98(97-99)$ & $95(93-96)$ \\
\hline 3 & Man & 54 & Extremities & 0.8 & No & III & $100(100-100)$ & $99(99-99)$ & $97(97-98)$ \\
\hline 4 & Woman & 60 & Head/neck & 0.9 & No & II & $100(100-100)$ & $99(98-99)$ & $96(95-97)$ \\
\hline 5 & Man & 70 & Trunk & 1.0 & Yes & IV & $98(98-99)$ & $86(84-88)$ & $75(72-78)$ \\
\hline 6 & Man & 45 & Extremities & 1.5 & Yes & III & $99(99-99)$ & $92(91-93)$ & $84(82-86)$ \\
\hline 7 & Woman & 75 & Head/neck & 2.2 & No & III & $99(98-99)$ & $89(87-91)$ & $79(77-82)$ \\
\hline 8 & Man & 39 & Trunk & 3.7 & Yes & IV & $95(94-96)$ & $76(73-78)$ & $62(59-65)$ \\
\hline 9 & Man & 80 & Trunk & 5.0 & No & III & $94(93-95)$ & $73(70-75)$ & $58(55-61)$ \\
\hline 10 & Woman & 60 & Extremities & 7.0 & Yes & IV & $94(93-95)$ & $72(69-74)$ & $57(54-60)$ \\
\hline
\end{tabular}

95\% Cl: 95\% confidence interval

Data from the Swedish Melanoma Register 1990-2014 with follow-up until 31 Dec 2014 by the Swedish Cause of Death Registry. 


\section{Figures}

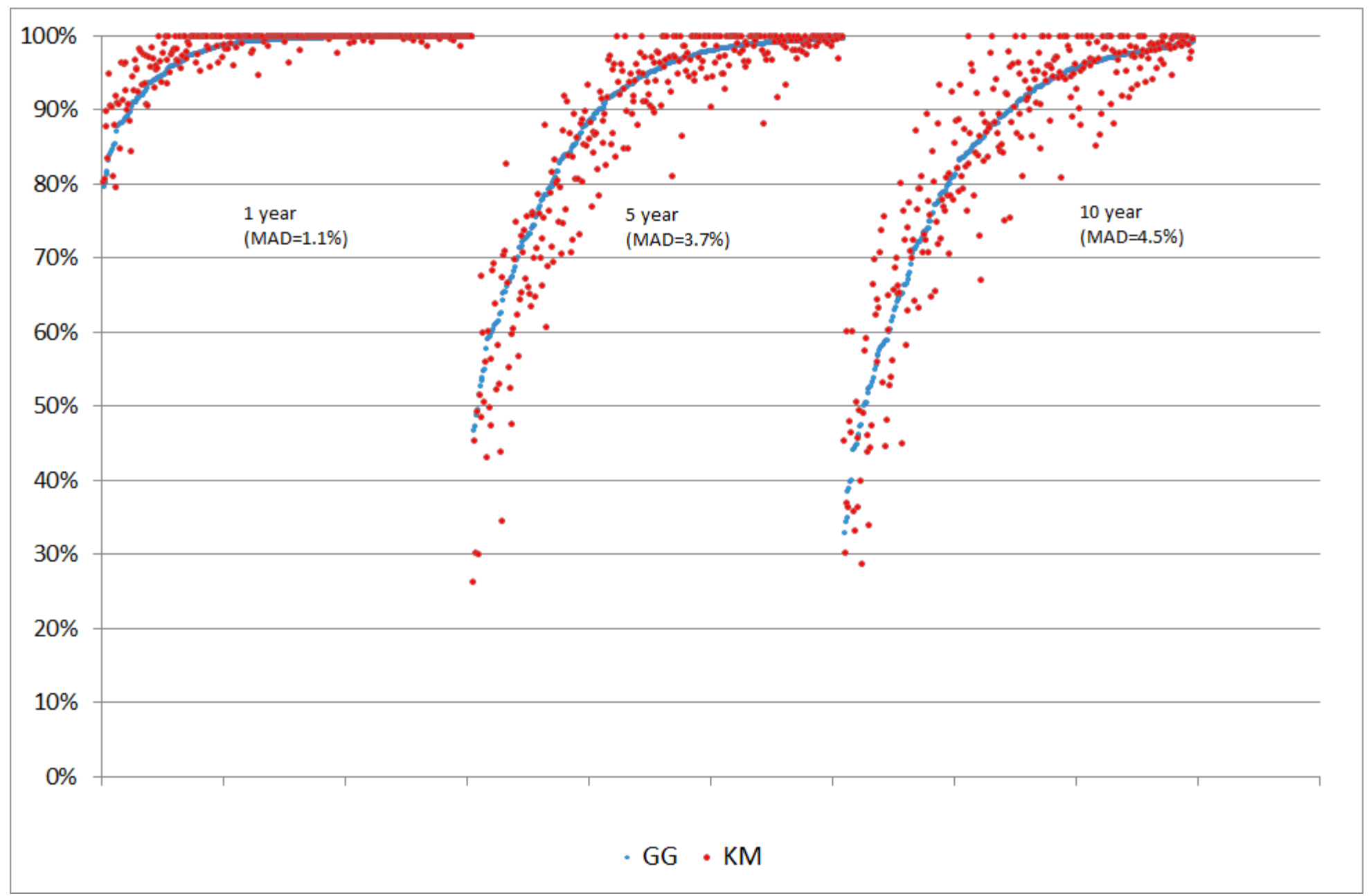

Figure 1. 1, 5 and 10 year survival probabilities from the Generalised Gamma (GG) method versus Kaplan-Meier (KM) estimates for combinations with $\geq 30$ observations. The blue dots represent the probabilities from GG and the red dots represent KM estimates. The mean absolute difference (MAD) between the red and blue dots is also presented in Table 3. 


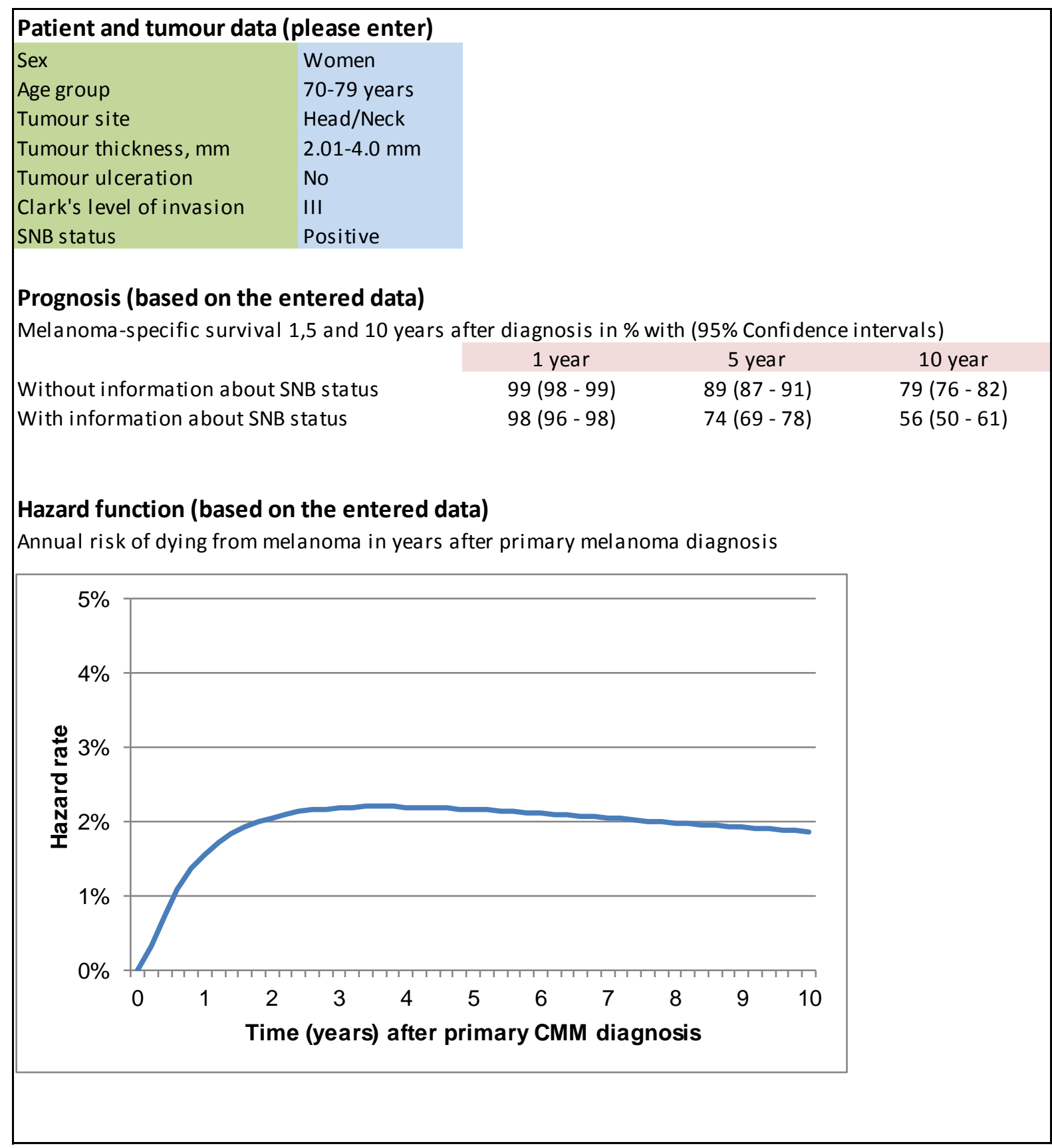

Figure 2. Overview of the prognostic instrument 